\title{
Framing Lifetime Income
}

\author{
Jeffrey R. Brown \\ University of Illinois at Urbana-Champaign \\ and NBER \\ brownjr@illinois.edu
}

\author{
Sendhil Mullainathan \\ Harvard University and NBER \\ mullain@fas.harvard.edu
}

\author{
Jeffrey R. Kling \\ Congressional Budget Office \\ and NBER \\ jeffrey_kling@nber.org \\ Marian V. Wrobel \\ Health Policy Commission \\ marian.wrobel@gmail.com
}

May 2013

Journal of Retirement, forthcoming

\begin{abstract}
We provide evidence that individuals optimize imperfectly when making annuity decisions, and this result is not driven by loss aversion. Life annuities are more attractive when presented in a consumption frame than in an investment frame. Highlighting the purchase price in the consumption frame does not alter this result. The level of habitual spending has little interaction with preferences for annuities in the consumption frame. In an investment frame, consumers prefer annuities with principal guarantees; this result is similar for guarantee amounts below, at, and above the purchase price. We discuss implications for the retirement services industry and its regulators.
\end{abstract}

We thank Abby Sussman for exceptional research assistance. An earlier draft of this paper, co-authored with Garth Wiens, was circulated under the title "Framing, Reference Points, and Preferences for Life Annuities." We are grateful to the Pew Charitable Trusts, MacArthur Foundation, the Mott Foundation, and the TIAA-CREF Research Institute for financial support. The views expressed in this paper are those of the authors and should not be interpreted as those of any of the organizations that funded this research or with whom the authors are affiliated. Financial disclosure: Jeffrey R. Brown serves as a Trustee for TIAA and has received compensation as a speaker from companies that sell retirement income products. 


\section{Introduction}

Due the confluence of the Great Recession, the entry of the earliest Baby Boomers into their retirement years, and other factors, retirement income security has risen to the top of the agenda for the retirement industry and the policymakers who regulate it. One of the important themes in this discussion is whether, when and how to provide guaranteed lifelong retirement income as a distribution option in 401(k)s and other retirement plans. It has been widely noted that most 401(k) participants do not have the option to annuitize their account balances within their plans upon retirement, and that participants are reluctant to utilize such an option even when it does exist. This has led to calls for policy interventions, such as requiring firms to offer annuities as the default payout option from 401(k) plans (Gale et al. 2008). ${ }^{1}$

Through the lens of neoclassical economics, it is tempting to suggest that the lack of demand for annuity products illustrates, by "revealed preference," that consumers prefer a lumpsum to an annuitized stream of benefits. ${ }^{2}$ If limited annuitization is the outcome of perfect optimization by consumers making choices in the absence of market failures, then there would be little reason for policymakers to be concerned. In such a world, public policies designed to promote annuitization would be unnecessary, at best, and value-destroying if costly to implement. In contrast, if consumers are imperfectly optimizing or markets are imperfect, then there may be scope for improving outcomes by encouraging annuitization through changes in public policy, products, communication or plan design.

This paper contributes to the new literature supporting the hypothesis that many consumers are optimizing imperfectly with respect to annuity choices. We briefly summarize this

\footnotetext{
${ }^{1}$ Throughout this paper, we use the term "annuity" as shorthand for a life annuity, i.e., a product that provides a lifecontingent stream of income.

${ }^{2}$ Roughly speaking, the idea of revealed preference, dating back to Samuelson (1938), is that we can infer consumer preferences by observing their purchase decisions.
} 
newly emerging literature that directly tests for the effect of behavioral biases in decision making about annuities. We then confirm that, as documented in our prior research (Brown et al. 2008), presenting annuities and other financial products using different frames (defined as different representations of the same financial choice) can significantly alter an individual's relative preferences for these products. Specifically, when alternative financial products are presented in a consumption frame, which highlights consequences for consumption over the lifecycle, annuities were strongly preferred to other types of financial products, including savings accounts. When these same product choices are presented in an investment frame, which focuses on risk and return features, savings accounts and other financial products were strongly preferred to annuities.

Imperfect optimization, as exemplified by the impact of framing on choices, is one of three main types of deviations from neoclassical assumptions, along with bounded self-control and nonstandard preferences (Congdon, Kling and Mullainathan, 2011). For annuities, Hu and Scott (2007) have hypothesized that demand may be limited by loss aversion — a particular type of nonstandard preference. A key feature of loss aversion is that there can be important effects of deviating from an established reference point. In this paper, we examine three potential reference points on the impact of framing: (i) the inclusion of the annuity purchase price in the consumption frame, (ii) the inclusion of initial monthly spending levels in the consumption frame, and (iii) the variation of levels of principal protection in the investment frame. We find that the framing results are robust to the inclusion of reference points, and that the reference points themselves provide little further predictive power. 


\section{Is the Low Demand for Annuities Consistent with Optimizing Models?}

Standard economic models of life-cycle spending patterns imply that the portfolio of a risk-averse individual should include a substantial portfolio share in life annuities as a hedge against uncertainty about length of life (e.g., Yaari 1965; Davidoff, Brown, and Diamond 2005). Because annuities offer a higher rate of return, conditional on survival, than non-annuitized versions of the same underlying asset, a consumer that cares only about own her consumption, and not about bequests, will find it optimal to fully annuitize under complete markets.

Yet few consumers voluntarily annuitize their retirement savings. A long line of research has arisen to explain this inconsistency between theory and real world behavior. The earliest work focused on high prices as a result of asymmetric information (e.g., Friedman and Warshawsky 1990; Mitchell et al. 1999). Others have highlighted the incomplete nature of existing annuity markets, including the absence of inflation protection (Brown, Mitchell, and Poterba 2002), the lack of insurance against consumption shocks like medical expenditures (Turra and Mitchell 2005; Sinclair and Smetters 2004), and the lack of exposure to the equity premium with annuitized wealth (Inkmann, Lopez and Michaelides 2011). Still others have considered pre-existing annuitization, (Dushi and Webb 2004), bequest motives (Lockwood 2012), risk sharing within families (Kotlikoff and Spivak 1981; Brown and Poterba 2000), the option value of delayed annuitization (Milevsky and Young 2007), and uncertainty about mortality parameters (Reichling and Smetters 2013).

A number of these papers have shown that it is possible to rationalize very low demand for life annuities under certain conditions. For example, Lockwood (2012) finds that a combination of realistic pricing loads and moderate bequest motives can render annuities unattractive in an optimizing model. Dushi and Webb (2004) combine high prices, high levels of 
preexisting annuities, and risk sharing within couples and find those factors can simulate low average demand. Inkmann, Lopes and Michaelides (2011) show, using a realistically calibrated model of U.K. consumers, that many households would optimally choose not to purchase fixed annuities because of the flexibility associated with investment in the stock market. Koijen, Nijman and Werker (2011) also emphasize the role of illiquidity in a model that allows for time varying interest rates, inflation and risk premia, along with mortality risk, and show that a market limited to fixed annuity contracts does not allow consumers to optimally allocate their resources.

These and other papers illustrate that it is possible to explain low average levels of annuity purchases in an optimizing model. Not all of these models, however, are fully satisfactory for at least two reasons. First, they often highlight or create other puzzles. For example, a number of the product-based objections have been at least partially addressed within the industry by new products (e.g., annuities with inflation-protected payments, annuities linked with long-term care insurance, etc.) and yet take-up of these products remains low. Similarly, explanations that rely on private market imperfections are unable to explain why so few individuals are willing to delay claiming Social Security benefits, which provides an opportunity to purchase inflation-indexed annuities priced based on population mortality (Coile et al. 2002). Second, although these models can explain the low average level of annuitization, it remains difficult to explain the cross-sectional variation in who chooses to annuitize (Brown et al. 2013).

Nonetheless, the literature leaves open the possibility that low levels of observed annuity demand may be optimal. Of course, the fact that it is possible to explain low annuity levels in a particular optimizing model does not mean that such a model is necessarily the correct one. In 
light of this, researchers have recently begun to use experiments and surveys to directly examine whether or not individuals are, in fact, optimizing perfectly. ${ }^{3}$

Tversky and Kahneman (1986, p. S253) emphasized that "an essential condition for a theory of choice that claims normative status is the principle of invariance: different representations of the same choice problem should yield the same preference." Thus, when researchers can show that decisions violate the invariance principle, it is possible to reject that consumers are engaging in perfectly optimizing. At least three papers have shown that annuitization decisions are sensitive to framing. In prior work (Brown et al. 2008), which we confirm and extend in this paper, we showed that consumers are more likely to indicate a preference for a life annuity when it is presented in a frame that emphasizes consumption, relative to a frame that emphasizes investment features. Agnew et al. (2008) randomized descriptions of annuities in neutral, positive, or negative frames relative to other investment products. When these individuals subsequently participated in an investment game, the negatively framed individuals were less likely to select annuities in the game. Brown, Kapteyn and Mitchell (forthcoming) show that the decision to delay claiming of Social Security benefits is highly sensitive to framing.

Evidence of non-optimizing behavior is not limited to framing, however. If individuals are engaging in perfectly optimizing behavior, then the choice of a default option should not influence outcomes-yet available evidence suggests that defaults do affect annuitization behavior. For example, Holden and Nicholson (1998) show that the passage of ERISA in 1974, which required that the default payout option from a defined benefit plan be a joint-and-survivor annuity, increased the fraction of married men choosing a joint-and-survivor annuity by roughly

\footnotetext{
${ }^{3}$ Those interested in a more thorough review of the behavioral anomalies associated with annuitization are encouraged to read Benartzi, Previtero and Thaler (2011).
} 
25 percentage points. Aura (2005) reports that a 1984 change to require spousal consent to waive the survivor benefits further increased the use of joint-and-survivor annuities by an additional ten percentage points. Butler and Teppa (2007) examine ten Swiss companies and show that annuitization rates are greater than $50 \%$ for 8 of the 9 firms that use an annuity as a default payout option, versus under $10 \%$ for the firm that uses a lump-sum as the default.

Brown et al. (2013) provide experimental evidence that individuals have difficulty valuing annuities and that this difficulty - rather than a preference for lump-sums - may help explain observed low levels of annuity purchases. Overall, their results suggest that individuals may be resorting to simplified heuristics to evaluate the complex annuity decision, rather than behaving in a manner consistent with the maximization of a lifetime utility function.

\section{Research Design}

\subsection{Overview of our Approach}

The consumption frame encourages the individual to think in terms of a stream of spending: this frame uses the terms "spend" and "payments," mentions only the amount of money generated each month, and keeps the underlying financial details (like rate of return) implicit. The investment frame instead invites the individual to think in terms of wealth accumulation: this frame repeatedly uses the terms "invest" and "earnings", explicitly mentions rate of return, describes the potential for early withdrawal, and characterizes the final investment value upon death for a set of different financial products, including both life annuities and savings accounts.

These two alternative frames may lead to different perceptions of gains and losses. In the consumption frame, annuities appear to provide insurance against a (consumption) loss, namely 
the reduction in monthly spending in the event of a long life. On the other hand, in the investment frame annuities appear to create the risk of an (investment) loss, namely the reduction in total wealth due to premature death. To explore the possibility that loss aversion is a possible reason for limited annuity demand, as suggested by Hu and Scott (2007), we rely on a key insight of prospect theory: that individuals often behave in a discontinuous manner around a reference point. In understanding how someone will respond to choices that generate welfare changes, it is important to identify how individuals conceive of their starting positions, which in some cases is assumed to be intrinsic to the individual, and in other cases is believed to be introduced directly by the framing of the choice.

We extend our work by examining three reference points. First, our earlier work found that preferences for life annuities in comparison to alternative financial products were more than three times higher in the consumption frame than the investment frame. The investment frame explicitly mentions the dollar value of the fixed initial amount required to purchase each type of product being compared, which may function as a reference point for assessing the potential for losses, perhaps by creating an endowment effect. In the consumption frame this equivalent dollar value is merely implicit, described only as an undefined "portion of savings", although the underlying products and their incomes are identical and all products are described as being actuarially fair. In this paper we introduce the initial purchase price for each financial product into the consumption frame without adding any investment language, in order to test the effect of this obvious investment-oriented reference point on the previously observed increase in preference for annuities under the consumption frame.

Second, we explore whether or not there is a reference point effect in the consumption frame. We are interested in whether the introduction of a habitual monthly consumption level 
into the hypothetical scenarios might provide people with a baseline against which to calculate the consumption gains and losses. By varying the initial level of monthly consumption described in the different scenarios, we can ensure that some, all, or none of the available financial choices can successfully meet these desired spending levels, and we can see how averse people are to losing some of their prior consumption.

Finally, we test how demand for a principal-protected annuity (i.e., one that guarantees return of the nominal value of their initial investment) compares to that of an actuarially equivalent life annuity without such a guarantee. We also examine whether initial purchase price serves as an especially strong reference point when setting amount of principal-protection.

\subsection{Survey Methods}

We collected data using the internet survey firm Zoomerang, which recruited respondents over age 50 from a pre-existing panel of individuals willing to participate in surveys in return for small incentives. Our first four-arm survey was conducted in December 2007 and is described in an earlier paper (Brown et al. 2008); the data on 673 individual participants from two of these original four arms are used in this paper. Our second seven-arm internet survey was conducted in April 2008, and included a total of 3,382 respondents, or approximately 483 per arm (ranging from 406 to 606). Across the full sample in this paper, participants were $43 \%$ female and $57 \%$ male, with $54 \%$ over age 60 and $34 \%$ over age $65.75 \%$ of respondents had children, $54 \%$ were married, and 76\% rated their health as "good" or better.

In all arms of both surveys respondents answered seven forced-choice questions. Each question described the investment/spending decisions of two fictitious people and asked, "Who has made the better choice?" The exact wording of the products and the frames used in the different arms is provided in Appendix A. All arms had a number of features in common; for 
example, the choices were always described in terms of amounts and durations, while specific financial terms like "annuity", "savings account", or "bond" were never introduced. In all arms, a life annuity paying $\$ 650$ each month until death was compared to several alternatives: (1) a traditional savings account bearing 4 percent interest (2) a consol bond paying $\$ 400$ each month forever (3) a 35-year period annuity paying \$500 each month, and (4) a 20-year period annuity paying $\$ 650$ each month. In the arms using the investment frame, an additional choice was used: a principal-protected life annuity (i.e., a life annuity that guaranteed enough payments so that the nominal value of the principal would be repaid even in the event of an early death) paying $\$ 625$ each month until death. Respondents were told that all choices were actuarially equivalent, and this was true in almost all cases (the principal-protected annuity with varying amounts of guaranteed repayment would need to provide slightly different monthly payments to be actuarially equivalent, but this small variation was ignored). To avoid spurious effects, the surveys included some comparisons that did not feature the life annuity, varied the order of the comparisons, and varied whether the life annuity was presented first or second within a given comparison.

Individuals were randomly assigned to each survey arm, which, in turn, used either a consumption or an investment frame. Briefly, the consumption frame emphasized how much each product would ultimately allow its purchaser to consume and for how long, using words such as "spend" and "payment," describing periods in terms of the purchaser's age, and never alluding to an account or its value. The investment frame emphasized the return on an account by using words such as "invest" and "earnings," describing periods in terms of years, mentioning the value of the initial investment $(\$ 100,000$ in every case), and alluding to the account value at other points in the description. Further detail about the frames, survey design, and validity of 
using stated rather than revealed preferences can be found in our earlier paper and references therein (Brown et al. 2008). The new survey questions are included as an appendix to this paper.

\section{New Evidence on Framing and Reference Points}

\subsection{Highlighting the Purchase Price in the Consumption Frame}

Our first reference point test introduces the $\$ 100,000$ purchase price of the different financial products into the consumption frame and compares the effect on annuity preferences of this modified frame to those of our original consumption and investment frames. In Table 1, we see that $68 \%$ of respondents prefer the $\$ 650$ per month provided by a life annuity to the consumption stream provided by a savings account of comparable actuarial value when both products are described using the modified consumption frame, as compared with $72 \%$ when described in the original consumption frame and $21 \%$ when described in the original investment frame. Similar fractions of the respondents exposed to the modified consumption frame preferred the life annuity to receiving $\$ 650$ per month for 20 years (79\%); the life annuity to receiving $\$ 500$ per month for 35 years (73\%); and the life annuity to receiving a consol bond that pays $\$ 400$ forever $(70 \%)$.

In all four cases, the proportion of respondents preferring the life annuity under the modified consumption frame was not statistically different from the proportion under the original consumption frame that did not clearly specify the purchase price. Yet the proportions under both consumption frames are substantially different, and statistically significant, from the proportion preferring the life annuity to the alternative products in the investment frame. Thus, even when we allow for the $\$ 100,000$ purchase price to serve as a possible reference point for measuring gains and losses of the different financial products, the consumption-oriented 
language of the modified consumption frame is sufficient to shift survey respondents' preferences significantly towards the life annuity.

\subsection{Consumption Reference Points}

In Table 2, we introduce an initial monthly spending level into the consumption frame in order to test whether initial spending creates a consumption-based reference point. Recall that in our consumption frames, individuals are endowed with a monthly Social Security benefit of $\$ 1,000$. Thus, the three monthly spending amounts used $(\$ 1,200, \$ 1,500$, and $\$ 1,800)$ were chosen to have a differential relationship to the consumption streams that are afforded by the different available financial products in combination with expected Social Security payments. Specifically, the $\$ 1,200$ spending level could be achieved by combining Social Security with any of the product options. At the other extreme, the $\$ 1,800$ spending level could not be financed by any of these products. The intermediate stream $(\$ 1,500)$ could be financed by some of the products (e.g., the annuity), but not by others (e.g., the savings account). For comparison, in column 1 we report the proportion preferring the annuity in the consumption stream when no reference is made to any initial spending level.

With the $\$ 1,200$ monthly amount, which could be provided for by any of the products, $80 \%$ of respondents prefer the life annuity to a savings account, versus $72 \%$ when no monthly spending is mentioned. Although this difference is statistically significant, the proportion falls to only $75 \%$ when the monthly spending amount is set at $\$ 1,500$, an amount that can be financed by the annuity but not by the savings account. When the monthly spending level is set at $\$ 1,800$, which cannot be reliably financed by any of the products, the proportion preferring an annuity falls to $72 \%$. When life annuities are compared to the other financial products, the inter-arm differences are smaller, less consistent, and generally insignificant. 
Overall, the absence of any clear patterns when the dollar amount of monthly spending targeted is varied suggest that this information is not serving an important role in establishing consumption-based reference points or that respondents' evaluation of financial decisions is independent of such reference points. Even so, within a realistic range of expected monthly spending levels for the hypothetical retirees, survey respondents continue to consistently prefer life annuities as a financial product when presented in a consumption frame.

\subsection{Guaranteed Return of Principal}

Our third reference point test varies the guaranteed return of a principal-protected annuity within the investment frame. In Table 3, we show that in the investment frame there is a strong preference for some principal protection. Specifically, we compare the proportion of the sample preferring a principal-protected life annuity to a savings account and the proportion preferring a simple life annuity with no principal protection to the same savings account. Consistent with individuals perceiving annuities as risky when they are framed as an investment (e.g., the investment payoff of the annuity is highly uncertain because it depends on how long one lives), we find that the proportion of individuals preferring the annuity is approximately twice as high when the annuity guarantees a return of principal.

We also varied the degree of principal protection, evaluating $\$ 80,000, \$ 90,000, \$ 100,000$ and $\$ 110,000$. If the original purchase price of the annuity $(\$ 100,000)$ is an important reference point around which consumers exhibit an asymmetry in their responsiveness to gains and losses, as predicted by prospect theory, then we would expect a discontinuity in the proportions valuing principal protection around the $\$ 100,000$ amount. We do not find any statistically significant effect. Although the point estimate of the proportion preferring the principal protected annuity does peak where the principal protection is for the original purchase price, the differences in 
proportions by size of the principal guarantee are not statistically significant. Still, the significant difference in the fraction of people preferring the principal-protected annuity to a savings account and the fraction preferring the life annuity in the same comparison (differences of 21 to 26 percentage points, depending on the amount of guaranteed repayment by the principalprotected annuity) suggest that individuals are averse to the potential loss of principal, albeit not with a sharply defined reference point at the purchase price.

\subsection{Multivariate Analysis}

As a final methodological note, our survey was designed so that individuals were randomly recruited across arms. Ex post, the randomization procedure was imperfectly balanced with respect to age and gender. As a result, we confirmed our key results using multivariate analysis. For example, in unreported results, we have used linear probability models to confirm the univariate findings regarding the effects of framing and to determine whether any individual characteristics affected either the likelihood of choosing an annuity over another product or the effect of framing on this choice. Characteristics included in the regression included gender, age, marital status, children, and health status. In general, the multivariate models confirmed the univariate findings, and the demographic variables had no effects with one exception. In the investment frame, females had a lower preference than males for the life annuity and for the principal-protected annuity. ${ }^{4}$ In the consumption frame, this difference between the genders was not observed. Therefore, effect of framing was slightly larger for females than for males. Overall, however, the multivariate results simply confirm our main findings: namely, that framing matters, that reference points appear to have very little effect on these findings, and that principal protection is attractive in an investment frame.

\footnotetext{
${ }^{4}$ Our previous article reported that there were not statistically significant differences between the genders. This finding emerged with larger sample sizes.
} 


\section{Conclusions and Policy Discussion}

This paper builds contributes to the growing literature supporting the hypothesis that individuals are not making annuitization decisions by perfectly maximizing utility of consumption over their life cycle. We providing evidence confirming our prior finding that stated annuity preferences are subject to framing effects, and that annuities appear more attractive when the context emphasizes consumption than investment. We also show that this result persists even when the initial purchase price is also mentioned in the consumption frame, confirming that the main driver of the effect is the overall difference in framing language and not specifically the mention of the purchase price. This finding is important to establishing the practical relevance of our result, because while it would be possible to fund an annuity via incremental contributions, in the majority of cases an annuity buyer is acutely conscious of the purchase price.

We tested whether introducing a monthly spending target would lead individuals to prefer an annuity specifically because they allow the purchaser to maintain a pre-existing level of consumption for life as opposed to products that require either a drop in consumption or the risk of running out of money altogether. We did not find that preferences were sharply inflected in this way, suggesting that, when viewed in a consumption frame, annuities can be appealing to a wide range of consumers, not just those with a specific relationship between their retirement income gap and their asset balance.

Individuals prefer an annuity that guarantees the return of principal as opposed to an annuity in which the bulk of principal can be lost in the event of early death. This finding is consistent with the prediction of $\mathrm{Hu}$ and Scott (2007) that loss-averse consumers would prefer principal-protected products. However, in contrast to loss aversion theory, we find that survey respondents' preferences are not sharply inflected around the exact purchase price, i.e., it is not 
particularly important for return of the full principal $(\$ 100,000)$ as opposed to a slightly smaller amount (e.g. $\$ 80,000)$ to be guaranteed. Although individuals value principal protection, they do not especially value protection of the exact amount of the initial investment. This finding dovetails with the emergence and popularity of many new financial products that blend lifecontingent payments with a variety of guarantees but not necessarily return of principal per se.

There are several practical implications of our findings. First, these results indicate that the typical 401(k) plan's emphasis on wealth accumulation may be creating an environment that conditions individuals to prefer lump-sums over annuities. Second, within an investment framework, annuities appear more attractive when they include principal protection, an insight that may explain why consumers who do annuitize are often partial to including period certain guarantees in their products, despite the fact that these guarantees essentially reduce the insurance value of the products. Third, were plans to instead emphasize consumption features of retirement planning, such as by reporting account accumulations in the form of monthly retirement income projections rather than as account balances, life annuities may look more attractive to participants. If so, then policies requiring such disclosures might have a significant impact on annuitization propensities. Fourth, these results suggest that annuity decisions will be sensitive to the wording of participant communication. Subtle changes in wording may make annuities look more or less attractive relative to alternative payout options. Finally, and perhaps most importantly, these results add to the body of knowledge suggesting that the observed consumer reluctance to annuitize should not be interpreted as evidence that lump-sum options are preferable to annuities. 


\section{References}

Aura, Saku. 2005. "Does the Balance of Power Within a Family Matter? The Case of the Retirement Equity Act.” Journal of Public Economics, 89(9-10): 1699-1717.

Agnew, Julie R., Lisa R. Anderson, Jeffrey R. Gerlach and Lisa R. Szykman. 2008. "Who Chooses Annuities? An Experimental Investigation of the Role of Gender, Framing, and Defaults." American Economic Review, 98(2): 418-422.

Benartzi, Shlomo, Alessandro Previtero and Richard H. Thaler. 2011. "Annuitization Puzzles." Journal of Economic Perspectives, 25(4): 143-164.

Brown, Jeffrey R., Arie Kapteyn, Erzo F.P. Luttmer, and Olivia S. Mitchell. 2013. "Do Consumers Know How to Value Annuities? Complexity as a Barrier to Annuitization." Unpublished paper.

Brown, Jeffrey R., Arie Kapteyn and Olivia S. Mitchell. Forthcoming. "Framing and Claiming: How Information-Framing Affects Expected Social Security Claiming Behavior." Journal of Risk and Insurance.

Brown, Jeffrey R., Jeffrey R. Kling, Sendhil Mullainathan, and Marian V. Wrobel. 2008. "Why Don't People Insure Late-Life Consumption? A Framing Explanation of the UnderAnnuitization Puzzle." American Economic Review, 98(2): 304-309.

Brown, Jeffrey R., Olivia S. Mitchell and James M. Poterba. 2002. "Mortality Risk, Inflation Risk, and Annuity Products." In Innovations in Retirement Financing, ed. Olivia S. Mitchell, et al., 175-197. University of Pennsylvania Press.

Brown, Jeffrey R. and James M. Poterba. 2000. "Joint Life Annuities and the Demand for Annuities by Married Couples." Journal of Risk and Insurance, 67(4): 527-553.

Bütler, Monika and Frederica Teppa. 2007. "The Choice between an Annuity and a Lump Sum: Results from Swiss Pension Funds.” Journal of Public Economics, 91(10): 1944-1966.

Coile, Courtney, Peter Diamond, Jonathan Gruber, and Alain Jousten. 2002. "Delays in Claiming Social Security Benefits," Journal of Public Economics, 84(3):357-85.

Congdon, William C., Jeffrey R. Kling, and Sendhil Mullainathan. 2011. Policy and Choice: Public Finance Through the Lens of Behaviorial Economics. Brookings Institution Press.

Davidoff, Thomas, Jeffrey R. Brown and Peter A. Diamond. 2005. "Annuities and Individual Welfare.” American Economic Review, 95(5), 1573-1590.

Dushi, Irena, and Anthony Webb. 2004. "Household Annuitization Decisions: Simulations and Empirical Analysis.” Journal of Pension Economics and Finance, 3(2): 109-143.

Friedman, Benjamin M., and Mark J. Warshawsky. 1990. "The Cost of Annuities: Implications for Saving Behavior and Bequests.” Quarterly Journal of Economics, 105(1): 135-154.

Gale, William G., J. Mark Iwry, David C. John and Lina Walker. 2008. "Increasing Annuitization in 401(k) Plans with Automatic Trial Income." Retirement Security Project Paper No. 2008-02.

Holden, Karen, \& Nicholson, Sarah. 1998. "Selection of a Joint-and-Survivor Pension." University of Wisconsin Institute for Research on Poverty Discussion Paper No. 1175-98. 
$\mathrm{Hu}$, Wei-Jin and Jason S. Scott. 2007. "Behavioral Obstacles in the Annuity Market." Financial Analysts Journal, 63(6): 71-82.

Inkmann, Joachim, Paula Lopes, and Alexander Michaelides. 2011. "How Deep is the Annuity Market Participation Puzzle?” Review of Financial Studies, 24(1): 279-319.

Koijen, Ralph S.J., Theo E. Nijman, and Bas J. M. Werker. 2011. “Optimal Annuity Risk Management." Review of Finance, 15(4): 799-833.

Kotlikoff, Laurence J. and Avia Spivak. 1981. "The Family as an Incomplete Annuities Market." Journal of Political Economy, 89(2): 372-391.

Lockwood, Lee M. 2012. "Bequest Motives and the Annuity Puzzle." Review of Economic Dynamics, 15(2): 226-243.

Milevsky, Moshe A. and Virginia R. Young. 2007. "Annuitization and Asset Allocation." Journal of Economic Dynamics and Control, 31(9): 3138-3177.

Mitchell, Olivia S., James M. Poterba, Mark J. Warshawsky and Jeffrey R. Brown. 1999. "New Evidence on the Money's Worth of Individual Annuities." American Economic Review. 89(5): 1299-1318.

Reichling, Felix and Kent Smettters. 2013. "Optimal Annuitization with Stochastic Mortality Probabilities." Unpublished paper.

Samuelson, Paul. 1938. "A Note on the Pure Theory of Consumers' Behaviour.” Economica 5:61-71.

Sinclair, Sven H. and Kent A. Smetters. 2004. "Health Shocks and the Demand for Annuities." Congressional Budget Office Technical Paper No. 2004-09.

Turra, Cassio M. and Olivia S. Mitchell. 2005. "The Impact of Health Status and Out-of-Pocket Medical Expenditures on Annuity Valuation." University of Michigan Retirement Research Center Research Brief No. 2005-079.

Tversky, Amos and Daniel Kahneman. 1986. "Rational Choice and the Framing of Decisions." Journal of Business, 59(4): 251-278.

Yaari, Menahem E. 1965. "Uncertain Lifetime, Life Insurance, and the Theory of the Consumer." Review of Economic Studies, 32(2): 137-150. 


\section{Table 1}

Respondents Preferring Annuities to Alternative Products (Percent)

Type of Frame

$\begin{array}{ccc} & & \text { Modified Consumption } \\ \text { Investment } & \text { Consumption } & \$ 100,000 \text { Initial } \\ \text { Frame } & \text { Frame } & \text { Investment } \\ (1) & (2) & (3)\end{array}$

Life annuity (\$650 per month) compared to:

Traditional savings account

$4 \%$ interest 21

$\begin{array}{lll}21 & 72 & 68\end{array}$

20-year period annuity

$\$ 650$ per month 48

$\begin{array}{lll}48 & 77 & 79\end{array}$

35 -year period annuity

$\$ 500$ per month $\quad 40$

$76 \quad 73$

Consol bond

$\$ 400$ per month forever

$\mathrm{N}$

406

Survey Arm

IB

IA

IIA

Notes: Each question described two fictitious men's decisions for investing/spending in retirement and asked, "Who has made the better choice?" All decisions were described in terms of amount and duration; the terms "annuity", "savings account", and "bond" were not used to label decisions. The Investment frame(Arm IB) used terms such as "invest" and "earnings," described periods in terms of years, mentioned the value of the initial investment (\$100,000 in every case), and alluded to the account value at other points in the survey. The Consumption frame (Arm IA) used terms such as "spend" and "payment," described periods in terms of the individual's age, and never alluded to an account or its value. The Modified Consumption frame (Arm IIA) is the same as the Consumption frame, with the added mention of the initial payment (\$100,000 in every case) and added allusions to this account value at other points in the survey. Survey Arms IA and IB were collected via an internet survey in December 2007; Survey Arm IIA was collected in a separate internet survey in April 2008. Standard errors range from 2.0 to 2.8 percentage points. 


\section{Table 2}

Respondents Preferring Annuities to Alternative Products in a Consumption Frame (Percent) Monthly Spending Reference Point

No monthly
spending
mentioned

(1)

\section{Life annuity (\$650 per month) compared to:}

Traditional savings account

$4 \%$ interest

72

77

$\$ 650$ per month

35 -year period annuity

$\$ 500$ per month

Consol bond

$\$ 400$ per month forever

$\mathrm{N}$

Survey Arm
$\$ 1200$ monthly spending

(2)
$\$ 1500$ monthly spending (3)
\$1800 monthly spending

(4)

Notes: Each question described two fictitious men's decisions for investing/spending in retirement and asked, "Who has made the better choice?" All decisions were described in terms of amount and duration; the terms "annuity", "savings account", and "bond" were not used to label decisions. Arm IA is described in the notes for Table 1. Arms IIB, IIC, and IID are identical to Arm IA except for the introduction of suggested monthly spending amounts as noted in the table headings above. Survey Arms IA was collected via an internet survey in December 2007; Survey Arms IIB-IIS were collected in a separate internet survey in April 2008. Standard errors range from 1.7 to 2.8 percentage points. 


\section{Table 3}

Respondents Preferring Annuities to a Savings Account in an Investment Frame (Percent)

Survey Arm

(1) (2) (3)

(3)

(4)

Life annuity compared to a traditional savings account with $4 \%$ interest:

$\$ 625$ annuity per month with $\$ 80,000$ principal protection

$\$ 625$ annuity per month with $\$ 90,000$ principal protection

$\$ 625$ annuity per month with $\$ 100,000$ principal protection

$\$ 625$ annuity per month with $\$ 110,000$ principal protection

$\$ 650$ annuity per month with no principal protection

$\mathrm{N}$

Survey Arm
44

46

47

20

24

499

606

IIF
43

21

22

$321 \quad 447$

IB IIG

Notes: Each question described two fictitious men's decisions for investing/spending in retirement and asked, "Who has made the better choice?" All decisions were described in terms of amount and duration; the terms "annuity", "savings account", and "bond" were not used to label decisions. Arm IB is described in the notes for Table 1. Arms IIE, IIF, and IIG are identical to Arm IB except for varying the guaranteed return in principal-protected life annuity. Survey Arm IB was collected via an internet survey in December 2007; Survey Arms IIE-IIG were collected in a separate internet survey in April 2008. Standard errors range from 1.7 to 2.8 percentage points. 


\section{Appendix A: Text of Survey Instrument}

\section{$\underline{\text { Investment Frame }}$}

1. The language in bold is varied as noted in the four investment frames (Arms IIE, IIF, IA, IIG).

Introduction

On the following screens you will be asked seven questions. In each case, two people have made permanent decisions on how to invest a portion of their money in retirement. You are asked to judge which person has made a better choice. In all scenarios, each person has some savings and receives $\$ 1,000$ each month in social security, in addition to the portion of savings mentioned in each question. Each person has chosen a different way to invest this portion $(\$ 100,000)$ of their savings. They have already set aside money to leave for their children when they die. The choices are intended to be financially equivalent and based on personal preferences for investing in retirement.

Life annuity

Mr. Red: Mr. Red invests $\$ 100,000$ in an account which earns $\$ 650$ each month for as long as he lives. He can only withdraw the earnings he receives, not the invested money. When he dies, the earnings will stop and his investment will be worth nothing.

20-year period annuity

Mr. Orange: Mr. Orange invests $\$ 100,000$ in an account which earns $\$ 650$ each month for 20 years. He can only withdraw the earnings he receives, not the invested money. After 20 years, the earnings will stop and his investment will be worth nothing. However, if he dies before then, he may leave remaining earnings to charity.

\section{5-year period annuity}

Mr. Blue: Mr. Blue invests $\$ 100,000$ in an account which earns $\$ 500$ each month for 35 years. He can only withdraw the earnings he receives, not the invested money. After 35 years, the earnings will stop and his investment will be worth nothing. However, if he dies before then, he may leave remaining earnings to charity.

Consol bond

Mr. Green: Mr. Green invests \$100,000 in an account which earns a 5\% interest rate. He can only withdraw the interest he receives, not the invested money. When he dies, he may leave the remaining earnings, which continue forever, to charity.

$\underline{\text { Savings account }}$

Mr. Gray: Mr. Gray invests $\$ 100,000$ in an account which earns a 4\% interest rate. He can withdraw some or all of the invested money at any time. When he dies, he may leave any remaining money to charity.

\section{Principal-protected life annuity}

Mr. Black: Mr. Black invests \$100,000 in an account which earns \$625 each month for as long as he lives. He can only withdraw the earnings he receives, not the invested money. If he dies before he has received \$80,000 (or $\$ 90,000 / \$ 100,000 / \$ 110,000)$ in total payments, he may leave the difference to charity. 


\section{Consumption Frame}

1. The language in bold is only present in the modified consumption frame (Arm IIA).

2. The language in italics is only present and is varied as noted in the three consumption frames with monthly spending levels (Arms IIB, IIC, IID).

Introduction

On the following screens you will be asked seven questions. In each case, two people have made permanent decisions on how to spend a portion of their money in retirement. You are asked to judge which person has made a better choice.

In all scenarios, each person has some savings and can spend \$1,000 each month from social security in addition to the portion of income mentioned in each question. They are used to spending about $\$ 1,200$ (or $\$ 1,500 / \$ 1,800$ ) each month before retirement. Each person has chosen a different financial product for a portion $\mathbf{( \$ 1 0 0 , 0 0 0 )}$ of their savings. They have already set aside money to leave for their children when they die. The choices are intended to be financially equivalent and based on personal preferences for spending in retirement.

Life annuity

Mr. Red: Mr. Red pays \$100,000 at retirement so he can spend $\$ 650$ each month for as long as he lives in addition to social security. When he dies, there will be no more payments.

20-year period annuity

Mr. Orange: Mr. Orange pays $\$ \mathbf{1 0 0 , 0 0 0}$ at retirement so he can spend $\$ 650$ each month until he is 85 years old in addition to social security. When he turns 85 , he will have no additional money left to spend. However, if he dies before he is 85 , he may leave remaining payments to his children.

\section{5-year period annuity}

Mr. Blue: Mr. Blue pays $\mathbf{\$ 1 0 0 , 0 0 0}$ at retirement so he can spend $\$ 500$ each month until he is 100 years old in addition to social security. When he turns 100, he will have no additional money left to spend. However, if he dies before he is 100, he may leave remaining payments to his children.

\section{Consol bond}

Mr. Green: Mr. Green pays $\$ \mathbf{1 0 0 , 0 0 0}$ at retirement so he can spend $\$ 400$ each month for as long as he lives in addition to social security. When he dies, he may leave remaining payments, which will continue forever, to his children.

\section{$\underline{\text { Savings account }}$}

Mr. Gray: Mr. Gray pays $\mathbf{\$ 1 0 0 , 0 0 0}$ at retirement so he can choose an amount to spend each month in addition to social security. How long his money lasts depends on how much he spends. If he spends only $\$ 400$ per month, he has money for as long as he lives. When he dies, he may leave the remainder to his children. If he spends $\$ 650$ per month, he has money only until age 85 . He can spend down faster or slower than each of these options. 